\title{
Efeito do boro na nodulação da ervilha cultivada em solos de várzea ${ }^{(1)}$
}

\author{
Watson Rogério de Azevedo(2), Valdemar Faquin(2), Fátima Maria de Souza Moreira(2), \\ Antônio Claret de Oliveira Júnior(2) e Carolina Cardoso Lisboa(2)
}

\begin{abstract}
Resumo - O objetivo deste trabalho foi avaliar o efeito do boro na nodulação da ervilha (Pisum sativum L. cv. Torta de Flor Roxa), cultivada em solos de várzea em condições de casa de vegetação, entre maio e julho de 1998. Amostras de Neossolo Flúvico, Gleissolo Háplico, Gleissolo Melânico e Organossolo Mésico artificialmente drenado foram coletadas na camada de 0-20 cm. Essas amostras foram previamente cultivadas com rabanete, e receberam calcário, P, K, S, Cu e Zn e seis doses de B (0,0, 0,25, 0,5, $1,5,3,0$ e 6,0 $\left.\mathrm{mg} \mathrm{dm}^{-3}\right)$. Por ocasião do cultivo da ervilha aplicou-se apenas $\mathrm{K}\left(100 \mathrm{mg} \mathrm{dm}^{-3}\right)$. $\mathrm{O}$ delineamento experimental foi inteiramente casualizado, em esquema fatorial 4x6, com três repetições. Foram cultivadas três plantas por vaso, cujas sementes, na época da semeadura, foram submetidas à inoculação com estirpes de Rhizobium leguminosarum (BR 618 e BR 619). Para verificação da existência de estirpes nativas de rizóbio, cultivaram-se sem inoculação nas sementes, três vasos, de cada solo, que haviam recebido a mesma dose de calcário, a mesma adubação básica e $0,5 \mathrm{mg} \mathrm{dm}^{-3}$ de boro. Aos 45 dias após o plantio, em pleno florescimento, colheu-se o experimento. Não foram observadas estirpes nativas nos solos avaliados. Nos solos Gleissolo Háplico e Organossolo Mésico artificialmente drenado, as doses de $\mathrm{B}$ influenciaram a nodulação e a atividade da nitrogenase.
\end{abstract}

Termos para indexação: inoculação, Rhizobium leguminosarum, simbiose, nitrogenase.

\section{Boron effects on nodule development in pea plants cultivated in lowland soils}

\begin{abstract}
The objective of this work was to evaluate the effect of boron on nodule development in pea Pisum sativum L. plants cultivated in lowland soils under greenhouse conditions from May to July, 1998. Samples of Alluvial Soil, Low Humic Gley, Humic Gley and artificially drained Bog Soil were collected from a layer $0-20 \mathrm{~cm}$ deep. The samples were previously cultivated with radish plants that received lime, $\mathrm{P}, \mathrm{K}, \mathrm{S}, \mathrm{Cu}$ and $\mathrm{Zn}$ and doses of $\mathrm{B}\left(0,0.25,0.5,1.5,3.0\right.$ and $\left.6.0 \mathrm{mg} \mathrm{dm}^{-3}\right)$. Before pea cultivation only $\mathrm{K}$ was applied $\left(100 \mathrm{mg} \mathrm{dm}^{-3}\right)$. The experimental design was totally randomized in a factorial scheme $4 \times 6$ with three replicates. Seeds were inoculated with Rhizobium leguminosarum strains (BR 618 and BR 619). To verify native strains, three pots of each soil were cultivated without inoculated seeds with same lime and fertilizers doses and $0.5 \mathrm{mg} \mathrm{dm}^{-3}$ of boron. After 45 days, the experiment was harvested. Native strains were not found in the evaluated soils. Boron affected nodule development and nitrogenase activity in the pea plants in Low Humic Gley and artificially drained Bog Soil.
\end{abstract}

Index terms: inoculation methods, Rhizobium leguminosarum, symbiosis, nitrogenase.

\section{Introdução}

A região sul de Minas Gerais possui um potencial de 200.000 ha de várzeas irrigáveis que têm sido utilizadas principalmente na época das águas, para o cultivo de arroz inundado. Essas áreas, devidamente

\footnotetext{
(1) Aceito para publicação em 18 de setembro de 2001. Trabalho financiado pelo CNPq.

(2) Universidade Federal de Lavras, Dep. de Ciência do Solo, Caixa Postal 37, CEP 37200-000 Lavras, MG. E-mail: watsonra@ufla.br,vafaquin@ufla.br, fmoreira@ufla.br, acoliveirajr@hotmail.com, carolalisboa@bol.com.br
}

drenadas e manejadas no período da seca, oferecem possibilidades de diversificação de culturas com até duas ou mais colheitas anuais. Segundo Reis (1989) e Moraes \& Dynia (1992), o cultivo de espécies como feijão, trigo e ervilha, nesse período, possibilitaria a maximização da exploração dessas várzeas.

Embora apresentem topografia e disponibilidade de água favoráveis, os solos de várzea são ácidos e deficientes em nutrientes, principalmente N, P, Ke B (Andrade, 1997; Faquin et al., 1998; Corrêa, 1999; Fernandes, 1999; Villa, 1999; Azevedo et al., 2000), o que torna a aplicação de calcário e fertilizantes práti- 
cas necessárias à exploração econômica dessas áreas, sob condições de drenagem.

Segundo Peres et al. (1989), o cultivo da ervilha, em diversas regiões do Brasil, tornou-se uma alternativa economicamente viável a partir dos estudos de manejo e seleção de variedades realizadas pela Embrapa-Centro Nacional de Pesquisa de Hortaliças. Por se situarem em região de clima ameno, as várzeas da região sul de Minas Gerais são propícias ao cultivo dessa leguminosa e proporcionam grandes produtividades quando irrigadas (Reis, 1989).

A ervilha pode associar-se simbioticamente com Rhizobium leguminosarum e se beneficiar da fixação do $\mathrm{N}$ atmosférico, o que reduz o custo de produção, além de diminuir os riscos de contaminação do lençol freático e dos mananciais, pelo uso intensivo dos fertilizantes nitrogenados em cultivos sucessivos. A fixação biológica do $\mathrm{N}_{2}$ é um processo redutor cuja enzima, a nitrogenase, é extremamente sensível ao oxigênio livre (Marschner, 1995). Como esse processo requer alta demanda de energia (ATP), ou seja, 16 moléculas de ATP são requeridas por cada molécula de $\mathrm{N}_{2}$ reduzido, o mesmo exige um eficiente sistema de regulação na pressão do $\mathrm{O}_{2}$ na célula. Assim, os microrganismos diazotróficos têm desenvolvido várias estratégias e mecanismos para proteger a enzima da inativação irreversível por oxigênio; isso inclui o controle da sua difusão através de barreiras mecânicas ou enzimáticas (Becana \& Rodriguez-Barrueco, 1989).

Na fixação biológica do $\mathrm{N}_{2}$, um mecanismo fisiológico determina a quantidade de oxigênio, responsável pelo processo de respiração celular, sem, no entanto, comprometer a atividade da enzima. Esse mecanismo pode estar ligado à atuação do B na parede celular, cuja importância reside na relação entre a membrana da leguminosa e do rizóbio (Bolaños et al., 1996). Segundo Vincent (1980), o B tem um papel estável, no sistema vascular, que permite um transporte de duas vias entre o nódulo e a planta. Cakmak \& Römheld (1997) afirmam que a atividade da nitrogenase é sensível à deficiência de $\mathrm{B}$, e o seu papel, na manutenção dessa atividade, é particularmente pronunciada na fixação do $\mathrm{N}_{2}$ por cianobactérias (Garcia-Gonzáles et al., 1990). Apesar disto, o papel do B na fixação de nitrogênio em leguminosas tem sido pouco estudado.
O objetivo desse trabalho foi avaliar o efeito do B na nodulação da ervilha cultivada em solos de várzea.

\section{Material e Métodos}

O experimento foi realizado em casa de vegetação do Departamento de Ciência do Solo da Universidade Federal de Lavras (Ufla), Lavras, MG. Cultivaram-se plantas de ervilha (Pisum sativum L. cv. Torta de Flor Roxa), no período de maio a julho de 1998, em amostras da camada superficial $(0-20 \mathrm{~cm})$ de quatro classes de solos de várzea, representativos do sul de Minas Gerais: Neossolo Flúvico (RU), Gleissolo Háplico (GX), Gleissolo Melânico (GM) e Organossolo Mésico artificialmente drenado (OY).

Os atributos químicos e físicos das amostras naturais dos solos encontram-se na Tabela 1 .

Antes do cultivo da ervilha, foi cultivado rabanete, em vasos de $3 \mathrm{dm}^{3}$, onde se cultivaram quatro plantas, colhidas aos 28 dias de semeadura. $\mathrm{O}$ delineamento experimental foi inteiramente casualizado, em esquema fatorial $4 \times 6$, sendo quatro classes de solos de várzea conforme referido e seis doses de $\mathrm{B}\left(0,0,0,25,0,5,1,5,3,0\right.$ e $\left.6,0 \mathrm{mg} \mathrm{dm}^{-3}\right)$ na forma de $\mathrm{H}_{3} \mathrm{BO}_{3}$, com quatro repetições.

A correção da acidez foi realizada com a aplicação de $\mathrm{CaCO}_{3}$ e $\mathrm{MgCO}_{3}$ p.a., na relação Ca:Mg de 4:1. As doses aplicadas, baseadas na curva de incubação em ensaio preliminar em laboratório, visando elevar a saturação por bases a 70\%, foram 4,4, 2,7, 7,8 e 3,5 $\mathrm{t} \mathrm{ha}^{-1}$, nos solos RU, GX, GM e OY, respectivamente. Aplicaram-se, em todos os

Tabela 1. Características químicas e físicas dos solos nativos (camada de 0-20 cm). Média de três repetições.

\begin{tabular}{|c|c|c|c|c|}
\hline \multirow[t]{2}{*}{ Características $^{(1)}$} & \multirow{2}{*}{$\begin{array}{l}\text { Neossolo } \\
\text { Flúvico }\end{array}$} & \multicolumn{3}{|c|}{ Gleissolo Gleissolo Organossolo } \\
\hline & & Háplico & Melânico & Mésico \\
\hline$\overline{\mathrm{pH}}$ & 5,1 & 4,9 & 4,6 & 4,9 \\
\hline $\mathrm{P}\left(\mathrm{mg} \mathrm{dm}^{-3}\right)$ & 5 & 2 & 8 & 6 \\
\hline $\mathrm{K}\left(\mathrm{mg} \mathrm{dm}^{-3}\right)$ & 86 & 32 & 78 & 102 \\
\hline $\mathrm{B}\left(\mathrm{mg} \mathrm{dm}^{-3}\right)$ & 0,26 & 0,32 & 0,25 & 0,26 \\
\hline $\mathrm{Ca}\left(\mathrm{mmol}_{\mathrm{c}} \mathrm{dm}^{-3}\right)$ & 29 & 5 & 8 & 15 \\
\hline $\operatorname{Mg}\left(\mathrm{mmol}_{\mathrm{c}} \mathrm{dm}^{-3}\right)$ & 17 & 2 & 2 & 9 \\
\hline $\mathrm{Al}\left(\mathrm{mmol}_{\mathrm{c}} \mathrm{dm}^{-3}\right)$ & 2 & 10 & 13 & 7 \\
\hline $\mathrm{H}+\mathrm{Al}\left(\mathrm{mmol}_{\mathrm{c}} \mathrm{dm}^{-3}\right)$ & 58 & 57 & 17 & 88 \\
\hline CTC efetiva $\left(\mathrm{mmol}_{\mathrm{c}} \mathrm{dm}^{-3}\right)$ & 50 & 18 & 26 & 35 \\
\hline CTC a pH 7,0 $\left(\mathrm{mmol}_{\mathrm{c}} \mathrm{dm}^{-3}\right)$ & 106 & 164 & 177 & 116 \\
\hline $\mathrm{m}(\%)$ & 4 & 55 & 54 & 21 \\
\hline $\mathrm{V}(\%)$ & 44 & 12 & 7 & 24 \\
\hline Matéria orgânica $\left(\mathrm{g} \mathrm{kg}^{-1}\right)$ & 42 & 33 & 243 & 37 \\
\hline Areia grossa $\left(\mathrm{g} \mathrm{kg}^{-1}\right)$ & 0 & 30 & 9 & 0 \\
\hline Areia fina $\left(\mathrm{g} \mathrm{kg}^{-1}\right)$ & 179 & 611 & 230 & 120 \\
\hline Silte $\left(\mathrm{g} \mathrm{kg}^{-1}\right)$ & 471 & 179 & 391 & 570 \\
\hline Argila $\left(\mathrm{g} \mathrm{kg}^{-1}\right)$ & 350 & 180 & 370 & 310 \\
\hline Superf. específica $\left(\mathrm{m}^{2} \mathrm{~g}^{-1}\right)$ & 137,4 & 120,8 & 334,6 & 180,7 \\
\hline Densidade do solo $\left(\mathrm{g} \mathrm{cm}^{-3}\right)$ & 0,76 & 1,05 & 0,40 & 0,64 \\
\hline
\end{tabular}

(1)Determinadas segundo Embrapa (1997). 
vasos, $70 \mathrm{mg}$ de $\mathrm{N} ; 300 \mathrm{mg}$ de P; $100 \mathrm{mg}$ de K; $44 \mathrm{mg}$ de S; 1,9 $\mathrm{mg}$ de Cu e 5,0 $\mathrm{mg}$ de $\mathrm{Zn}$ por $\mathrm{dm}^{3}$ de solo, na forma de sais p.a.: $\mathrm{NH}_{4} \mathrm{H}_{2} \mathrm{PO}_{4} ; \mathrm{KH}_{2} \mathrm{PO}_{4} ; \mathrm{Ca}\left(\mathrm{H}_{2} \mathrm{PO}_{4}\right) .2 \mathrm{H}_{2} \mathrm{O}$; $\mathrm{CaSO}_{4} \cdot 2 \mathrm{H}_{2} \mathrm{O}$; $\mathrm{CuSO}_{4} \cdot 5 \mathrm{H}_{2} \mathrm{O}$ e $\mathrm{ZnSO}_{4} \cdot 7 \mathrm{H}_{2} \mathrm{O}$. Após a colheita do rabanete, os solos de cada vaso foram secados, destorroados, peneirados em malha de $5 \mathrm{~mm}$, homogeneizados e colocados nos respectivos vasos. Em seguida, foram coletadas, de cada vaso, subamostras que foram peneiradas $(2 \mathrm{~mm}$ ), para análises químicas. Por ocasião do cultivo da ervilha com base na análise de solo, foram aplicados apenas $100 \mathrm{mg}$ de $\mathrm{K}$ por $\mathrm{dm}^{3}$, na forma de $\mathrm{KCl}$ (p.a.). Os teores médios de $\mathrm{B}$ nos solos após o cultivo do rabanete se encontram na Tabela 2.

Em seguida, foram semeadas seis sementes de ervilha, por vaso, sem tratamento químico, e infectadas com estirpes específicas de Rhizobium leguminosarum (BR 618 e BR 619). O delineamento estatístico utilizado foi o mesmo do experimento com o rabanete, mas, com três repetições, em vez de quatro.

Para verificação da existência de estirpes nativas de rizóbio que, possivelmente, nodulariam a ervilha, foram cultivados com essa leguminosa, paralelamente, mais três vasos, de cada classe de solo, com a mesma adubação básica usada para o rabanete, com exceção do $\mathrm{N}$, e apenas $0,5 \mathrm{mg} \mathrm{dm}^{-3}$ de boro.

Uma semana após a emergência, efetuou-se o desbaste, deixando-se três plantas por vaso. No período experimental, a umidade do solo foi mantida em torno de $60 \%$ do volume total de poros (Freire et al., 1980), por meio de pesagens diárias dos vasos e aplicação de água destilada quando necessário.

Aos 45 dias após plantio, em pleno florescimento, as plantas foram colhidas e separadas em raízes, caules + ramos e folhas. A fixação do $\mathrm{N}_{2}$ foi avaliada pela atividade da nitrogenase nas raízes noduladas intactas, por meio do

Tabela 2. Teores disponíveis de B $\left(\mathrm{mg} \mathrm{dm}^{-3}\right)$ extraído com água quente após a colheita do rabanete e antes da semeadura da ervilha em razão das doses de $\mathrm{B}\left(\mathrm{mg} \mathrm{dm}^{-3}\right)$ aplicada nos solos por ocasião do cultivo do rabanete.

\begin{tabular}{lllllll}
\hline Solo $^{(1)}$ & \multicolumn{7}{c}{ Dose de B } \\
\cline { 2 - 7 } & 0,00 & 0,25 & 0,50 & 1,50 & 3,00 & 6,00 \\
\hline RU & 0,48 & 0,81 & 0,91 & 1,55 & 2,75 & 5,30 \\
GX & 0,36 & 0,54 & 0,71 & 1,46 & 2,66 & 4,64 \\
GM & 0,47 & 0,66 & 0,91 & 1,32 & 1,88 & 3,97 \\
OY & 0,34 & 0,54 & 0,62 & 1,33 & 2,43 & 4,60 \\
\hline
\end{tabular}

${ }^{(1)}$ RU: Neossolo Flúvico; GX: Gleissolo Háplico; GM: Gleissolo Melânico; OY: Organossolo Mésico artificialmente drenado. método de redução de acetileno (Dilworth, 1966) em cromatógrafo Varian Star 3400-X. Nas folhas secadas em estufa a $65-70^{\circ} \mathrm{C}$ até peso constante, e moídas, analisaramse os teores de B, pela digestão via seca em forno de mufla a $500^{\circ} \mathrm{C}$ e determinação colorimétrica com Azometina- $\mathrm{H}$, e $\mathrm{N}$ total, pelo método micro-Kjeldahl (Malavolta et al., 1997).

Os dados obtidos foram submetidos à análise de variância e regressões, cujas equações foram ajustadas às médias do peso seco dos nódulos e às médias da atividade da nitrogenase específica em função das doses de B aplicadas.

\section{Resultados e Discussão}

As doses zero e $6,0 \mathrm{mg} \mathrm{dm}^{-3}$ proporcionaram sintomas visuais típicos de deficiência e toxidez de B, respectivamente. Os sintomas de deficiência foram observados na dose zero em todos os solos: a parte aérea das plantas mostrou redução significativa no porte, e alguns tecidos foliares apresentaram-se encarquilhados, cloróticos e com aspecto coriáceo. Esses sintomas são, provavelmente, resultado da acumulação de grandes quantidades de fenóis, que são a principal causa de danos celulares e da interrupção do crescimento em tecidos vegetais deficientes nesse nutriente. Pois, segundo Cakmak \& Röomheld (1997), a maioria dos fenóis conhecidos são tóxicos para as plantas, mesmo em baixa concentração.

As raízes das plantas-testemunhas apresentaramse levemente escurecidas e em menor quantidade em relação aos tratamentos que receberam $\mathrm{B}$, provavelmente pelo decréscimo da plasticidade das paredes celulares impedindo a divisão e elongação das células dos tecidos meristemáticos das raízes. Segundo Vaughan \& Ord (1990), maiores concentrações de ácidos fenólicos provavelmente influenciam negativamente o crescimento do eixo da raiz principal, bem como o número e o tamanho das raízes laterais.

O sintoma de toxidez nas folhas, verificado na dose $6,0 \mathrm{mg} \mathrm{dm}^{-3}$, caracterizou-se por clorose marginal nas folhas velhas, principalmente no terço inferior da planta. Essas manchas possuem concentração de B mais elevada, em comparação com o tecido adjacente a ela (Nable et al., 1997). Não foi observada nenhuma alteração nas raízes na dose $6,0 \mathrm{mg} \mathrm{dm}^{-3} \mathrm{se}$ comparada com as doses entre 0,25 a $3,0 \mathrm{mg} \mathrm{dm}^{-3}$. Segundo Nable (1988), as concentrações de B nas raízes, mesmo com alta disponibilidade de $\mathrm{B}$ no 
solo, continuam relativamente mais baixas do que nas folhas.

As raízes das plantas de todos os solos, nos tratamentos sem inoculação de rizóbio, avaliadas em pleno florescimento, não apresentaram nenhuma nodulação, indicando, assim, a inexistência de estirpes nativas de rizóbio capazes de nodular a ervilha.

Nas plantas infectadas, não ocorreu a nodulação das raízes das plantas nos solos RU e GM. A não-ocorrência de nódulos foi influenciada, provavelmente, pela presença de microrganismos antagônicos ou mesmo pelos níveis de mineralização de $\mathrm{N}$, principalmente no solo GM, que possui alto teor de matéria orgânica (Tabela 1). Segundo SylvesterBradley et al. (1980) e Aguirre \& Valdes (1993), a ocorrência de resposta variável à infecção, em solos de regiões tropicais, pode depender da espécie infectada e, até mesmo, do tipo de solo.

Nos solos GX e OY, a nodulação ocorreu nas raízes das plantas independentemente das doses de B aplicadas, principalmente no entorno da raiz principal. Nesses solos, na dose zero de B, os nódulos apresentaram-se de cor escura e de menor tamanho, provavelmente causadas por lesões nas paredes celulares, facilitando a difusão de oxigênio livre, prejudicial à enzima nitrogenase. Bolaños et al. (1994) observaram nódulos necróticos e não-funcionais na ausência de $\mathrm{B}$, afirmando que os danos na estrutura e função dos nódulos foram causados, provavelmente, pela degeneração das paredes celulares destes, incluindo a perimembrana do bacteróide.

Não houve diferenças morfológicas nas raízes das plantas entre as doses $0,25 \mathrm{a} 6,0 \mathrm{mg} \mathrm{dm}^{-3}$ em nenhum dos solos. Os nódulos presentes nos solos GX e OY, nessas doses, apresentaram-se em diferentes tamanhos e peso seco. Segundo Rahman et al. (1999), o B pode afetar as características dos nódulos, independentemente do efeito nas raízes ou nas plantas.

A relação entre o peso seco dos nódulos, das raízes das plantas nos solos GX e OY, e as doses aplicadas mostra um ajuste raiz quadrada em ambos os solos, o que indica que um menor valor nos pesos secos dos nódulos foi observado na dose zero (Figura 1), o que provavelmente foi causado pela degeneração das membranas e paredes celulares do bacteróide na ausência de B, conforme discutido anteriormente. Yamagishi \& Yamamoto (1994) tam- bém constataram menores valores de peso seco em nódulos de raízes de soja, na ausência de boro.

As doses de B, estimadas com relação ao peso seco máximo dos nódulos destacados das raízes das plantas, foram 1,85 e 2,34 $\mathrm{mg} \mathrm{dm}^{-3}$ nos solos GX e OY, respectivamente (Figura 1). A dose no solo GX foi $26,5 \%$ menor em relação à dose do solo OY, provavelmente por sua maior disponibilidade de B no solo GX em relação às doses aplicadas (Tabela 2). Essa maior disponibilidade pode ser atribuída ao valor da superfície específica, responsável por adsorver $\mathrm{B}$, que chega a ser $49,6 \%$ maior no solo OY.

Houve incrementos na atividade da nitrogenase nas doses mais baixas do micronutriente, levando a um ajuste raiz quadrada entre as variáveis, em ambos os solos, onde um decréscimo nas doses mais altas indica um possível efeito tóxico desse nutriente (Figura 2).

Na dose zero, em ambos os solos, apesar de conter uma pequena quantidade de B, essa, provavelmente, não foi suficiente para garantir a proteção das paredes dos envelopes que encerram a enzima, extremamente sensível ao oxigênio livre. Segundo

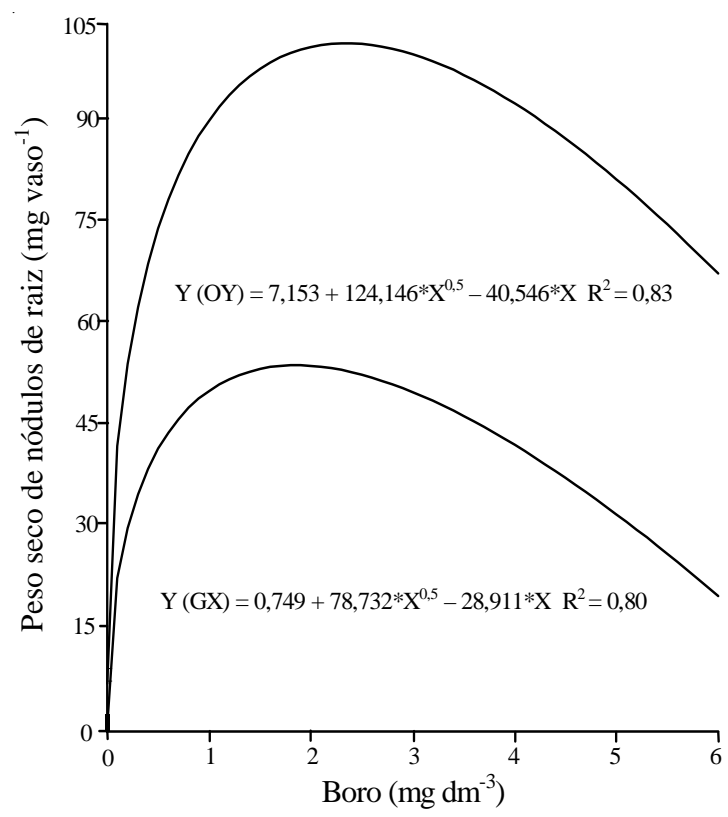

Figura 1. Peso seco de nódulo destacado de raiz de ervilha em razão da aplicação de B nos solos Gleissolo Háplico (GX) e Organossolo Mésico artificialmente drenado (OY). *Significativo a $5 \%$ de probabilidade. 
Cakmak \& Römheld (1997), o B, ao interagir com grupos $\mathrm{OH}$ dos glicopeptídeos na camada de polissacarídeos do envelope, contribui para o fortalecimento da barreira em relação à difusão do $\mathrm{O}_{2}$. Dalton et al. (1986) verificaram, em nódulos de soja, que a deficiência de $\mathrm{B}$ foi a causa da diminuição do nível de ácido ascórbico das células, o qual tem a função de proteger a nitrogenase contra o oxigênio livre tóxico. Bolaños et al. (1994), Yamagishi \& Yamamoto (1994), Bolaños et al. (1996) e Rahman et al. (1999) também observaram que na ausência de B a atividade da nitrogenase ficou comprometida. Recentemente, Bolaños et al. (2000) afirmam que na ausência de B, tanto o desenvolvimento da simbiose, como a evolução da nitrogenase em nódulos de ervilha, são danificados e retardados ao mesmo tempo.

A máxima atividade da nitrogenase nos nódulos secos 155,12 e $195,74 \mathrm{nmol} \mathrm{mg}^{-1} \mathrm{~h}^{-1}$ foi obtida com as doses 2,49 e 2,58 $\mathrm{mg} \mathrm{dm}^{-3} \mathrm{de} \mathrm{B}$, respectivamente, nos solos OY e GX (Figura 2). Doses, essas, muito próximas das que são necessárias para a máxima produção de matéria seca de vagens.

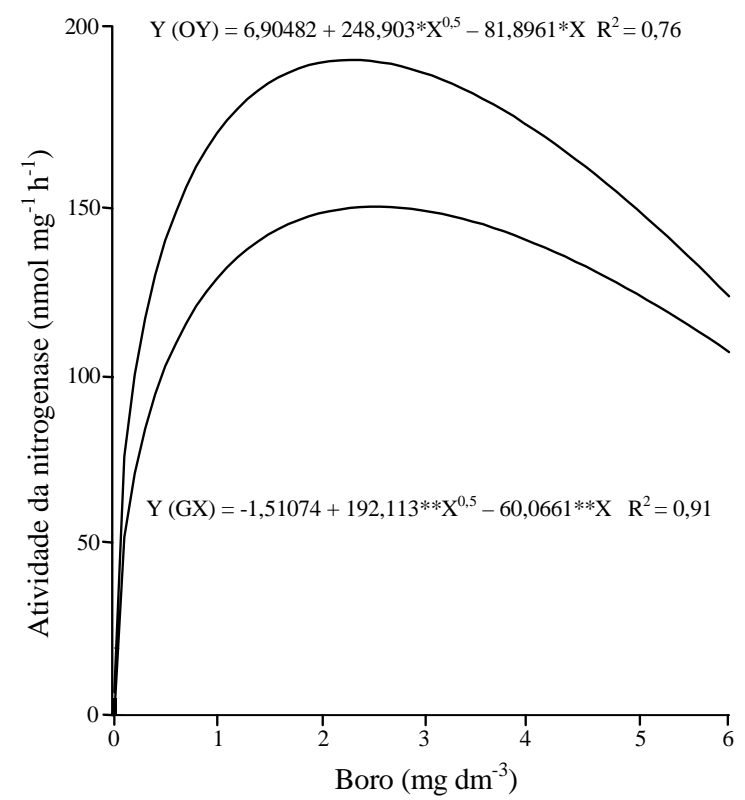

Figura 2. Atividade da nitrogenase específica de nódulos secos obtida pelo método de redução do acetileno em função da aplicação de B nos solos Gleissolo Háplico (GX) e Organossolo Mésico artificialmente drenado (OY). * e **Significativo a $5 \%$ e a $1 \%$ de probabilidade, respectivamente.
A atividade da enzima no solo OY apresentou-se aproximadamente $26,2 \%$ maior que no solo GX, resultado, este, esperado, já que o peso seco máximo estimado, no solo OY, foi aproximadamente, $49 \%$ maior que no solo GX. Provavelmente, o menor valor da densidade do solo OY contribuiu com uma menor resistência ao crescimento dos nódulos em relação ao solo GX (Tabela 1). Por outro lado, os teores de B, nas doses correspondentes, variaram pouco entre esses solos (Tabela 2).

Apesar de o teor do B nas plantas ter aumentado com o aumento das doses, houve grande variação dos valores entre os solos (Tabela 3). Assim, nos solos GX e OY, que tiveram suas raízes noduladas, os níveis de B no tecido foliar foram menores, provavelmente, devido aos atributos dos solos que, além de influenciar o crescimento das plantas, afetam também o coeficiente de utilização de $\mathrm{B}$, conferindo diferentes valores de nível crítico para as plantas.

Os teores de $\mathrm{N}$ variaram entre as doses de $\mathrm{B}$, em todos os solos, atingindo um valor adequado com a dose $1,5 \mathrm{mg} \mathrm{dm}^{-3} \mathrm{de} \mathrm{B}$, conforme a faixa de suficiência entre 4,0 a 5,0 $\mathrm{g} \mathrm{kg}^{-1}$ de $\mathrm{N}$ (Mills \& Jones Junior, 1996). Nas doses zero e $6,0 \mathrm{mg} \mathrm{dm}^{-3}$, os teores foliares estão abaixo do nível crítico de deficiência, $2,4 \mathrm{~g} \mathrm{~kg}^{-1}$ de N (Magalhães \& Giordano, 1989). Os baixos teores de $\mathrm{N}$, observados na dose zero, são ocasionados, provavelmente, pela própria deficiência de $\mathrm{B}$, a qual, afetando a estrutura das raízes, causou menor suprimento de $\mathrm{N}$ para as plantas. Na dose $6,0 \mathrm{mg} \mathrm{dm}^{-3}$, o teor de $\mathrm{N}$ reduziu-se muito, devido, provavelmente, à acumulação de B nas folhas. Mills

Tabela 3. Teores foliares de B e N total em ervilha cultivada em solos de várzea na época do pleno florescimento.

\begin{tabular}{lrrrrrr}
\hline Solo $^{(1)}$ & \multicolumn{6}{c}{ Dose de B $\left(\mathrm{mg} \mathrm{dm}^{-3}\right)$} \\
\cline { 2 - 7 } & 0,00 & 0,25 & 0,50 & 1,50 & 3,00 & 6,00 \\
\hline RU & 8,53 & 16,58 & 19,56 & 25,54 & 35,32 & 51,35 \\
GX & 4,04 & 4,81 & 7,29 & 12,94 & 27,20 & 49,60 \\
GM & 15,09 & 17,08 & 19,57 & 24,05 & 34,33 & 53,07 \\
OY & 4,14 & 4,97 & 6,97 & 15,26 & 16,75 & 28,85 \\
\hline \multirow{7}{c}{$\mathrm{N}\left(\mathrm{g} \mathrm{kg}^{-1}\right)$} \\
RU & 2,26 & 3,04 & 3,84 & 3,92 & 3,02 & 1,86 \\
GX & 2,14 & 3,10 & 3,58 & 4,06 & 3,14 & 1,98 \\
GM & 2,60 & 3,60 & 3,60 & 4,22 & 3,48 & 2,44 \\
OY & 2,38 & 2,94 & 3,02 & 4,06 & 3,22 & 1,92 \\
\hline
\end{tabular}

${ }^{(1)}$ RU: Neossolo Flúvico; GX: Gleissolo Háplico; GM: Gleissolo Melânico; OY: Organossolo Mésico artificialmente drenado. 
\& Jones Junior (1996) observaram, em folhas de parreira, deficiência de $\mathrm{N}$ que pôde ser observada como resultado de acumulação de B nas folhas. Já Chauhan \& Powar (1978) constataram que o teor de N, no tecido de plantas de ervilha, sofreu um acréscimo entre 2,7 a 3,6 $\mathrm{g} \mathrm{kg}^{-1}$ com o aumento da concentração de B na água de irrigação. Esses mesmos autores encontraram uma redução na produção quando a concentração de B estava entre $6,0 \mathrm{mg} \mathrm{dm}^{-3}$ e $8,0 \mathrm{mg} \mathrm{dm}^{-3}$.

\section{Conclusões}

1. Nos solos GX e OY a nodulação nas raízes das plantas de ervilha é influenciada pelas doses de boro.

2. A deficiência de B afeta a atividade da nitrogenase em nódulos de plantas de ervilha.

3. Altos teores de B proporcionam diminuição do teor foliar de nitrogênio.

\section{Referências}

AGUIRRE, F. F.; VALDES, M. Establecimiento y producción de Leucaena leucocephala inoculada com Rhizobium em um suelo ácido. Pasturas Tropicales, Cali, v. 15 , n. 2, p. 29-31, 1993.

ANDRADE, C. A. de B. Limitações de fertilidade e efeito do calcário para o feijoeiro (Phaseolus vulgaris L.) em solos de várzea do sul de Minas Gerais. 1997. $107 \mathrm{f}$. Tese (Doutorado em Fitotecnia) - Universidade Federal de Lavras, Lavras.

AZEVEDO, W. R.; FAQUIN, V.; FURTINI NETO, A. C. Boro em rabanete cultivado em solos de várzea: produção de matéria seca, níveis críticos nos solos e na planta. Ciência e Agrotecnologia, Lavras, v. 24, n. 5, p. 7-14, 2000.

BECANA, M.; RODRIGUEZ-BARRUECO, I. Protective mechanism of nitrogenase against oxygen excess and partially reduced oxygen intermediates. Physiologia Plantarum, Copenhagen, v. 75, p. 429-438, 1989.

BOLAÑOS, L.; BREWIN, N. J.; BONILLA, I. Effects of boron on rhizobium-legume cell-surface interactions and nodule development. Plant Physiology, Rockville, v. 110, p. 1249-1256, 1996.

BOLAÑOS, L.; ESTEBAN, E.; LORENZO, C. de; FERNÁNDEZ-PASCUAL, M.; FELIPE, M. R. de; GÁRATE, A.; BONILLA, I. Essentially of boron for symbiotic dinitrogen fixation in pea (Pisum sativum) rhizobium nodules. Plant Physiology, Rockville, v. 104, p. 85-90, 1994.

BOLAÑOS, L.; REDONDO-NIETO, M.; BONILLA, I. Boron-calcium relationship in nodulation and nodule organogenesis. In: PEDROSA, F. O.; HUNGRIA, M.; YATES, M. G.; NEWTON, W. E. (Ed.). Nitrogen fixation from molecules to crop productivity. Dordrecht: Kluwer Academic, 2000. 700 p.

CAKMAK, I.; RÖMHELD, V. Boron deficiency-induced impairments of cellular functions in plants. Plant and Soil, The Hague, v. 193, n. 1/2, p. 71-83, June 1997.

CHAUHAN, R. P. S.; POWAR, S. L. Tolerance of wheat and pea to boron in irrigation water. Plant and Soil, The Hague, v. 50, n. 1, p. 145-179,1978.

CORRÊA, F. S. Adubação nitrogenada e níveis críticos foliares de nitrogênio em feijoeiro cultivado em solos de várzea. 1999. 45 f. Dissertação (Mestrado em Solos e Nutrição de Plantas) - Universidade Federal de Lavras, Lavras.

DALTON, D. A.; RUSSEL, S. A.; HANUS, F. J.; PASCOE, G. A.; EVANS, H. J. Enzymatic reaction of ascorbate and glutathione that prevent peroxide damage in soybean root nodules. Proceedings of the National Academy of Sciences of The United State of America, Washington, v. 83, p. 3811-3815, 1986.

DILWORTH, M. J. Acetylene reduction by nitrogen-fixing preparations from Clostridium pasteuriamum. Biochimica et Biophysica Acta, Amsterdam, v. 127, p. 285-294, 1966.

EMBRAPA. Centro Nacional de Pesquisa de Solos (Rio de Janeiro, RJ). Manual de métodos de análise de solos. 2. ed. Rio de Janeiro, 1997, 212 p. (Documentos, 1).

FAQUIN, V.; ANDRADE, C. A. B.; FURTINI NETO, A. E.; ANDRADE, A. T.; CURI, N. Resposta do feijoeiro à aplicação de calcário em solos de várzea do sul de Minas Gerais. Revista Brasileira de Ciência do Solo, Campinas, v. 22, n. 4, p. 651-660, out./dez. 1998.

FERNANDES, L. A. Formas de alumínio, de fósforo e fosfatase ácida em solos de várzea cultivados com feijoeiro: influência de calagem e fósforo. 1999. $111 \mathrm{f}$. Tese (Doutorado em Solos e Nutrição de Plantas) - Universidade Federal de Lavras, Lavras.

FREIRE, J. C.; RIBEIRO, M. A. V.; BAHIA, V. G.; LOPES, A. S.; AQUINO, L. H. Resposta do milho em casa de vegetação a níveis de água em solos da região de Lavras-MG. Revista Brasileira de Ciência do Solo, Campinas, v. 4, n. 1, p. 5-8, 1980. 
GARCIA-GONZÁLES, M.; MATEO, P.; BONILLA, I. Effect of boron deficiency on photosynthesis and reductant sources and their relationship with nitrogenase activity in Anabaema PCC7119. Plant Physiology, Rockville, v. 93, p. 560-565, 1990.

MAGALHÃES, J. R.; GIORDANO, L. de B. Nutrição mineral da ervilha. Informe Agropecuário, Belo Horizonte, v. 14, n. 158, p. 9-16, mar. 1989.

MALAVOLTA, E.; VITTI, G. C.; OLIVEIRA, S. A. Avaliação do estado nutricional das plantas: princípios e aplicações. Piracicaba: Associação Brasileira para Pesquisa da Potassa e do Fosfato, 1997. 319 p.

MARSCHNER, H. Mineral nutrition of higher plants 2. ed. San Diego: Academic, 1995. 889 p.

MILLS, H. A.; JONES JUNIOR, J. B. Plant Analysis: handbook II. Athens: MicroMacro, 1996. 442 p.

MORAES, J. F. V.; DYNIA, J. F. Alterações nas características química e fisico-químicas de um solo Glei Pouco Húmico sob inundação e após a drenagem. Pesquisa Agropecuária Brasileira, Brasília, v. 27, n. 2, p. 223-235, fev. 1992.

NABLE, R. O. Resistance to boron toxicity amongst several barley and wheat cultivars: a preliminary examination of the resistance mechanism. Plant and Soil, The Hague, v. 112, n. 1, p. 45-57, 1988.

NABLE, R. O.; BAÑUELOS, G. S.; PAULL, J. G. Boron toxicity. Plant and Soil, The Hague, v. 193, n. 1/2, p. 181198, June 1997.

PERES, J. R. R.; SUHET, A. R.; VARGAS, M. A. T. Fixação de nitrogênio atmosférico pela ervilha em solos de cerrados. Informe Agropecuário, Belo Horizonte, v. 14, n. 158 , p. 19 , mar. 1989.
RAHMAN, M. H. H.; ARIMA, Y.; WATANABE, K.; SEKIMOTO, H. Adequate range of boron nutrition is more restricted for root nodule development than for plant growth in young soybean plant. Soil Science and Plant Nutrition, Tokyo, v. 45, n. 3, p. 287-296, 1999.

REIS, N. V. B. dos. Clima e a cultura da ervilha. Informe Agropecuário, Belo Horizonte, v. 14, n. 158, p. 8-9, mar. 1989.

SYLVESTER-BRADLEY, R.; OLIVEIRA, L. A. de; PODESTÁ FILHO, J. A. de; ST. JOHN, T. V. Nodulation of legumes, nitrogenase activity of roots and ocurrence of nitrogen-fixing Azospirillun spp. in representation soils of Central Amazon. Agro-Ecosystems, Amsterdam, v. 6, p. 249-266, 1980.

VAUGHAN, D.; ORD, B. Influence of phenolic acids on morphological changes in roots of Pisum sativum. Journal of the Science of Food and Agriculture, London, v. 52, p. 289-299, 1990.

VILLA, M. R. Potássio em solos de várzea e nutrição potássica do feijoeiro. 1999. 53 f. Dissertação (Mestrado em Solos e Nutrição de Plantas) - Universidade Federal de Lavras, Lavras.

VINCENT, J. M. Factors controlling the legumesrhizobium symbiosis. In: NEWTON, W. E.; ORMEJOHNSON, E. H. (Ed.). Nitrogen fixation. Baltimore: University Park Press, 1980. v. 3, p. 103-129.

YAMAGISHI, M.; YAMAMOTO, Y. Effects of boron on nodule development and symbiotic nitrogen fixation in soybean plants. Soil Science and Plant Nutrition, Tokyo, v. 40, v. 2, p. 265-274, 1994. 